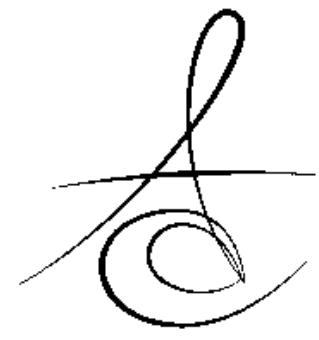

\section{EKTODERMAL DİSPLAZİLI HASTALARDA MULTİDİSİPLİNER YAKLAŞIM: 5 OLGU SUNUMU}

\section{ECTODERMAL DYSPLASIA WITH PATIENTS MULTIDISCIPLINARY APPROACH: 5 CASE REPORTS}

\author{
Dr. Mehmet Sinan DOĞAN* \\ Dr. Ahmet ARAS* \\ Dr. Zeki ARSLANOĞLU*** \\ Dr. Sedat GÜVEN ${ }^{* * * *}$
}

\section{Dt. Fatih DEMİRCí ${ }^{* * * *}$}

Makale Kodu/Article code: 2024

Makale Gönderilme tarihi: 16.12 .2014

Kabul Tarihi: 30.01.2015

\section{ÖZET}

Bu olgu sunumunda, ektodermal displazili vakalarda ağız ve diş sağı̆̆̆ yönünden görülen bozukluklar değerlendirildi ve sonuçları gözden geçirildi. Ektodermal displazi vakalarında klinik muayene ve radyolojik değerlendirmeler yapıldı. Çalışmada değerlendirilen 5 vakada diş eksikliği, kuru cilt, saç ve tırnak bozukluğu gibi ektodermal displazinin tipik klinik bulguları görüldü. Yaşları 6-15 arasında değişen 5 vakanın oral rehabilitasyonu sağlanarak hayat standartları yükseltilmeye çalışıldı. Diş hekimliğinde ektodermal displazi vakaları ayrıcalıklı bir yere sahiptir, bu yüzden çiğneme fonksiyonu, ortognatik, büyüme, ağız ve diş sağlığı yönünden profesyonel ve multidisipliner bir yaklaşım gerektirmektedir.

Anahtar Kelimeler: Ektodermal displazi, diş eksikliği.

\section{GİRIŞ}

Ektodermal displazi (ED), ektoderm tabakasından gelişen iki yada daha fazla dokunun anomalisi ile sonuçlanan heterojen nitelikte, bir grup hastalıktan oluşmaktadır. ${ }^{1-3}$ Literatürde 150 'den fazla türde ED tanımlanmıştır ve kalıtsal olarak aktarılabilmektedir ${ }^{4,5}$. Hastaların birçoğu normal yaşama kapasitesine ve zekaya sahiptirler. ${ }^{6}$ Bu hastalar için erken teşhis önemlidir çünkü bebekliğin erken dönemlerinde tükürük bezlerinin eksikliğinin farkına varılmaz ise beyin hasarı veya ölümle sonuçlanan hipertermiye neden olabilir. ${ }^{7}$ Tüm ırklarda 100.000 doğumda bir oranında görülen bir tablodur. ED'li hastaların \%90'ı erkektir. ${ }^{1,8}$

\section{ABSTRACT}

In this case report, ectodermal dysplasia cases seen in terms of oral and dental health disorders were evaluated and the results are reviewed. Cases of Ectodermal dysplasia clinical examination and radiological assessments were performed. Five cases evaluated in this study, missing teeth, dry skin, typical clinical manifestations of ectodermal dysplasia was seen as hair and nail disorders. Ages ranging from 615 five cases providing oral rehabilitation tried to raising living standards. Ectodermal dysplasia has a privileged place in dentistry so chewing function, orthognathic, growth, and requires a multidisciplinary approach in terms of professional oral and dental health.

keywords: Ectodermal dysplasia, missing teeth.

\footnotetext{
* Dicle Üniversitesi, Diş Hekimliği Fakültesi, Çocuk Diş hekimliği Anabilim Dalı

** Dicle Üniversitesi, Diş Hekimliği Fakültesi, Peridontoloji Anabilim Dalı

*** Mustafa Kemal Üniversitesi, Diş Hekimliği Fakültesi, Çocuk Dişhekimliği Anabilim Dalı

**** Dicle Üniversitesi, Diş Hekimliği Fakültesi, Protetik Diş Tedavisi Anabilim Dalı
} 
Atatürk Üniv. Diş Hek. Fak. Derg.

J Dent Fac Atatürk Uni

Supplement: 13, Yıl: 2015, Sayfa : 10-17
DOĞAN, TANİK, ARAS, TOPTANCI, ARSLANOĞLU, ERATILLA, GÜVEN, ATAŞ, DEMİRCI görünümü, çıkıntılı alın, semer burun, düşük yüz derinliği ve vertikal yüz yüksekliği gibi semptomları içermektedir. Ağız içi bulgularında ise ince alveoler kretler, süt ve daimi dişlenmede anadonti veya hipodonti görülebilmektedir. ED'nin en karekteristik bulguları anormal diş şekli ve hipodontidir. ${ }^{11}$ Diş eksikliği, yüz görünümü ve dış görünüm nedeniyle bu vakalarda sosyal ve psiko-sosyal problemler ortaya çıkabilmektedir. ${ }^{12}$

Konjenital diş eksikliği ve destekleyici alveolar kemiğin yokluğu, dental implant tedavileri için bir dezavantaj durum oluşturmaktadır. Bu nedenlerden dolayı hastalarda sıklıkla kemik greftleri ve sinus lifting operasyonları uygulanmaktadır. Kemik defektlerine ek olarak, yumuşak dokunun olmayışı final restorasyonların biyolojik uyumu için bir risk oluşturmakta ve estetik kaygılara neden olmaktadır. Uygun yumuşak doku augmentasyonları, serbest diş eti greftleri ve bağ doku greftleri ilerde dental implant restorasyonların çevresinde peri-implant dokuların devamlılı̆ını sağlamak için yapılmalıdır. Kemik greft işlemleri sonrasında uygun yumuşak doku greftleri ile kapatarak ideal bir doku konturu elde edilmelidir. ${ }^{13,14}$

Vakaların çene kemiklerinin bazal düzlemde boyutsal gelişimleri normal olmasına karşın, diş eksiklikleri sebebiyle alveol kretleri incedir ve kretlerin vertikal boyutları yeterli gelişememektedir. Dişlerin yokluğunda alveoler kretlerin gelişememesi dikey boyutta azalmaya ve dolayısıyla dudaklarda dışbükey görünüme sebep olmaktadır. Üst çenede damak genelde derindir ve dudak-damak yarığı görülebilmektedir. ${ }^{15,16}$

Erken multidisipliner dental müdahale çiğneme fonksiyonunu ve optimum yüz görünümünü geliştirme ve muhafaza etme açısından gereklidir. Protezlerin hazırlanmasındaki amaç, mevcut dişlerin korunması yanında, alveol kretlerindeki oluşabilecek rezorbsiyoları önlemektir. ${ }^{15}$

Erken müdahale çocukta konuşma, çiğneme ve yutkunmanın normal şekilde gelişmesi, normal temporomandibular eklem fonksiyonunun normal oluşmasının yanında genel olarak sağlıklı büyüme ve gelişmeye imkan verir. ${ }^{16}$

$\mathrm{Bu}$ olgu sunumunda kliniğimize diş eksikliği şikayetiyle başvuran ektodermal displazili olgu 1 ve 2 kardeş olmakla birlikte 5 hastanın oral rehabilitasyonunu içermektedir.

\section{OLGU 1}

6 yaşındaki kız çocuğu hastanın yapılan klinik ve radyolojik muayenesinde diş eksiklikleri ve diş çürükleri bulunduğu tespit edildi. Hastanın oral muayenesinde $54,55,51,61,64,65,36,75,71,71$ ve 85 no'lu dişler mevcuttur (Resim 1a). Radyolojik muayenesinde $11,21,14,15,16,24,25,26,35,37,35$ ve 36 nolu dişlerin gömülü olduğu görülmüştür (Resim 1e). Ayrıca hastanın dudaklarının çıkıntılı ve parmaklarında şekil bozukluğu olduğu fark edilmiştir (Resim 1b-1c). Akraba evliliğinin bulunmadığı hasta yakınının teyze çocuklarında da aynı durumun olduğu; fakat diğer aile bireyerinde herhangi bir problemin olmadığını belirtilmiştir. Hastanın fonksiyon, fonasyon ve estetik problemini iyileştirmek için alt ve üst çenesine hareketli parsiyel protez yapıldı (Resim 1d). Fiziksel büyüme göz önüne alınarak hasta 6 aylık periyotlarla kontrollerine devam edilmektedir.

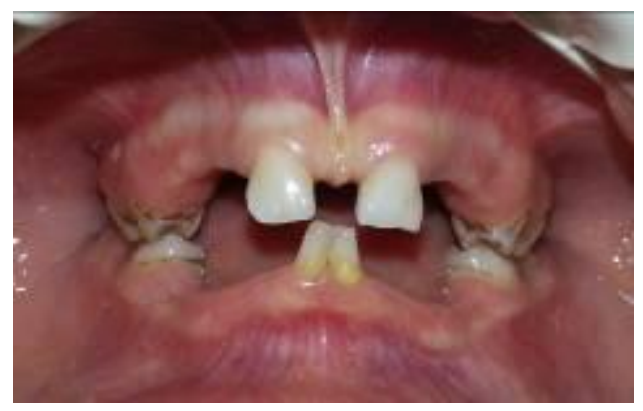

Resim 1a Hastanın tedavi öncesi görünümü

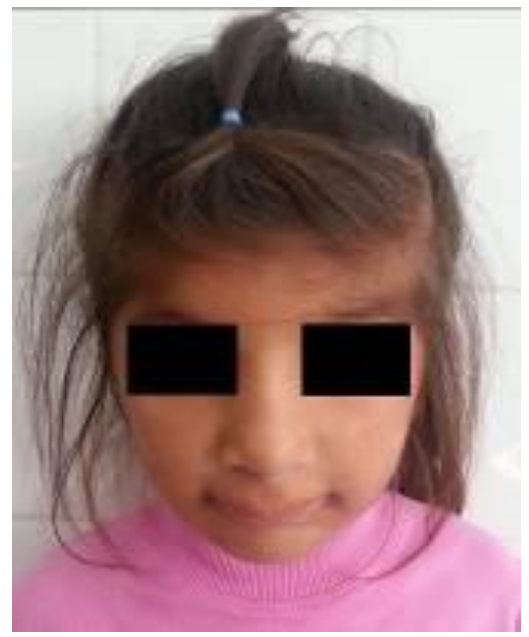

Resim 1b Hastanın frontal görünümü 
Atatürk Üniv. Diş Hek. Fak. Derg.

J Dent Fac Atatürk Uni

Supplement: 13, YIl: 2015, Sayfa : 10-17

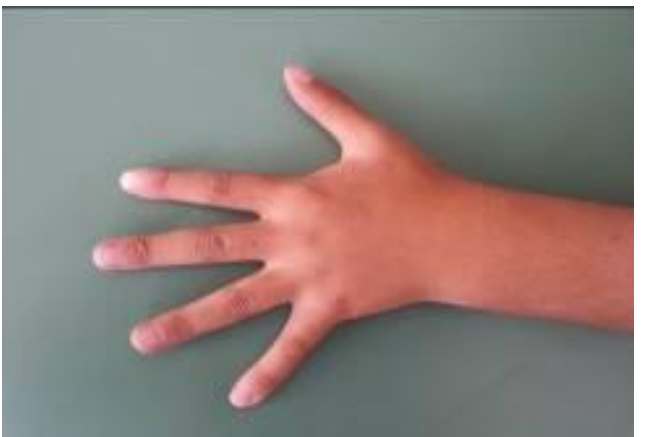

Resim 1c Hastanın ellerinin görünümü

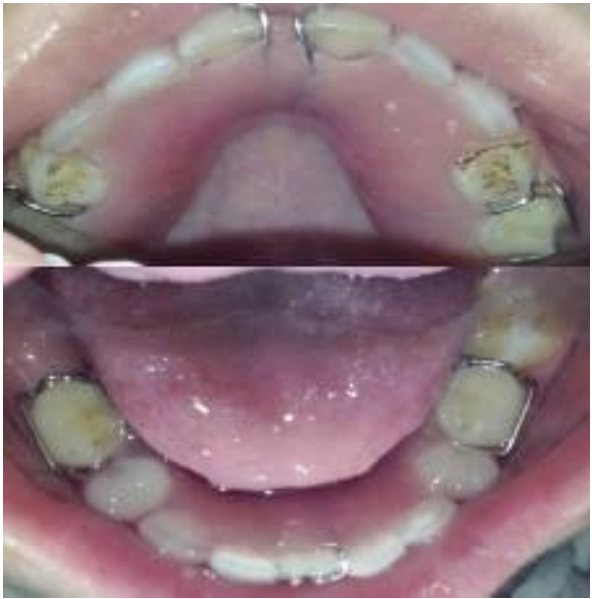

Resim 1d Protetik tedavi sonrası

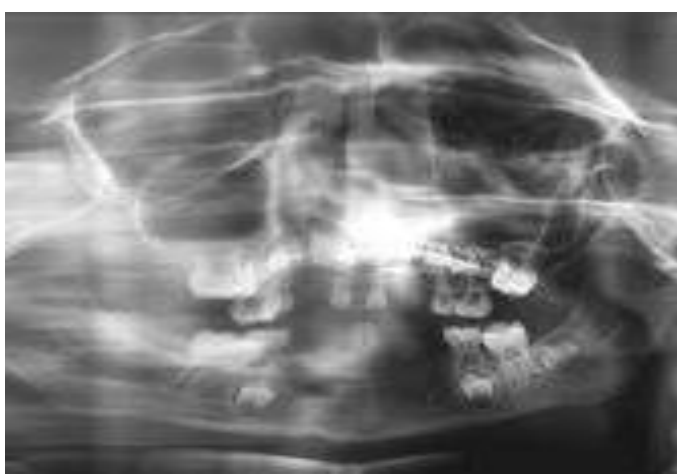

Resim 1e Hastanın panoramik radyografi görünümü

\section{OLGU 2}

9 yaşında erkek çocuk hastanın yapılan klinik ve radyolojik muayenesinde 12,22,31,32,33,41,42 ,43,44 nolu dişlerinin eksik ve 14,15,17,14,15,17,34,
DOĞAN, TANİK, ARAS, TOPTANCI, ARSLANOĞLU, ERATILLLA, GÜVEN, ATAŞ, DEMİRCI

35,37,35,37 nolu dişlerin ise gömük olduğu görülmektedir (Resim 2a-2b). Buna ek olarak hastada semer burun, çıkıntılı dudaklar ve kuru cilt fark edilmektedir (Resim 2c). Hastanın çürük dişlerinin restorasyonu yapıldı ve oral hijyen eğitimi verildi. Protetik değerlendirme sonrasında alt çeneye hareketli parsiyel protez uygulandı(Resim 2d). Kardeşi ile birlikte kontrollerine devam edilmektedir.

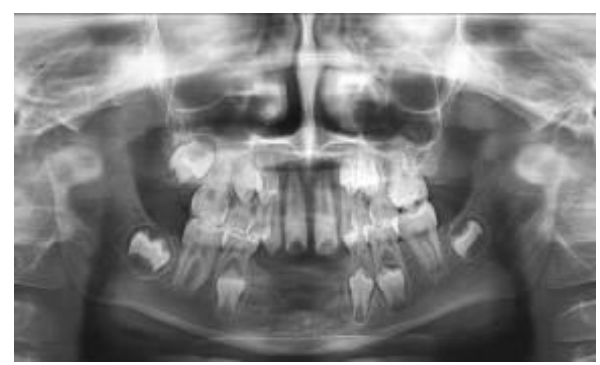

Resim 2a Panoramik röntgen

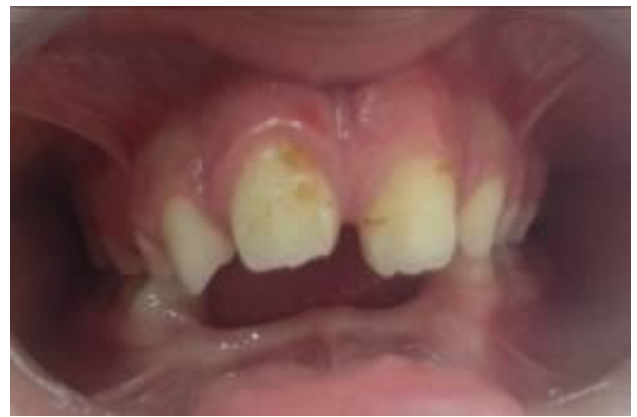

Resim 2b Hastanın intra-oral görünümü

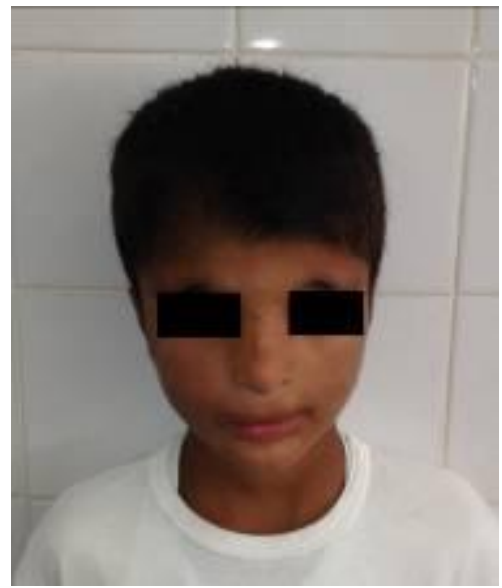

Resim 2c Hastanın frontal görünümü 
Atatürk Üniv. Diş Hek. Fak. Derg.

] Dent Fac Atatürk Uni

Supplement: 13, Yıl: 2015, Sayfa : 10-17

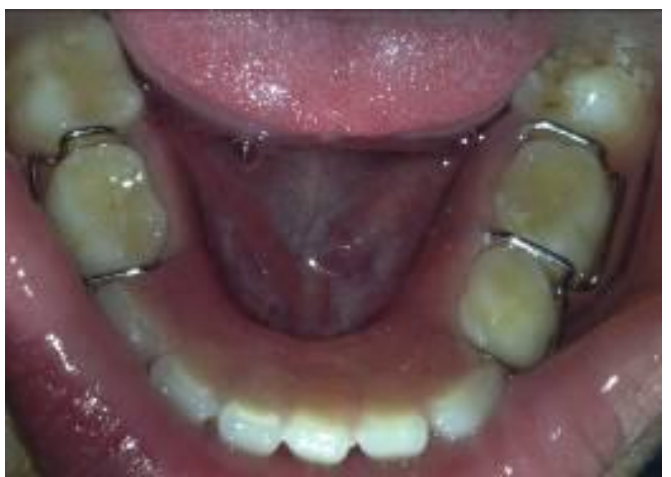

Resim 2d Protetik tedavi sonrası(Üst çene)

\section{OLGU 3}

15 yaşındaki Ektodermal displazili erkek çocuk hastanın yapılan klinik ve radyolojik muayenesinde alt ve üst çenede toplamda 10 adet dişe sahip olduğu tespit edilmiştir (Resim 3a, 3d). Hastanın ağız dışı muayenesinde semer burun, çıkıntılı dudaklar ve kuru cilt görülmektedir (Resim 3b). Hastanın çürük dişlerinin restorasyonu yapıldı ve oral hijyen eğitimi verildi. Protetik değerlendirme sonrasında hastaya alt ve üst çenelerine hareketli parsiyel protezler uygulandı. (Resim 3c).

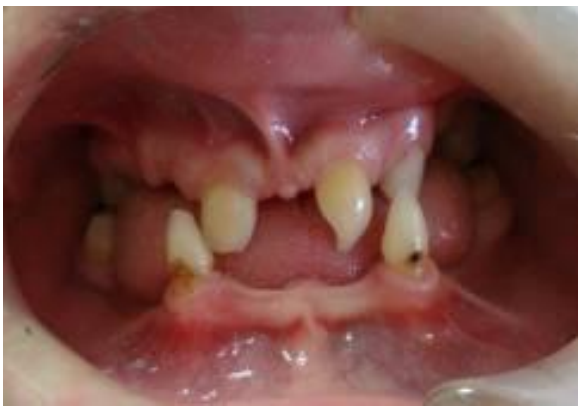

Resim 3a Hastanın tedavi öncesi görünümü

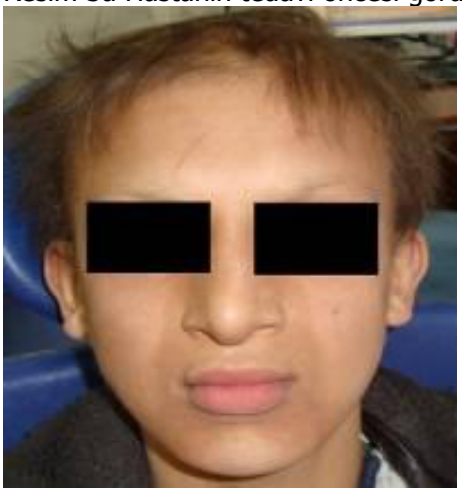

Resim 3b Hastanın frontal görünümü
DOĞAN, TANİK, ARAS, TOPTANCI, ARSLANOĞLU, ERATİLLA, GÜVEN, ATAŞ, DEMİRCI

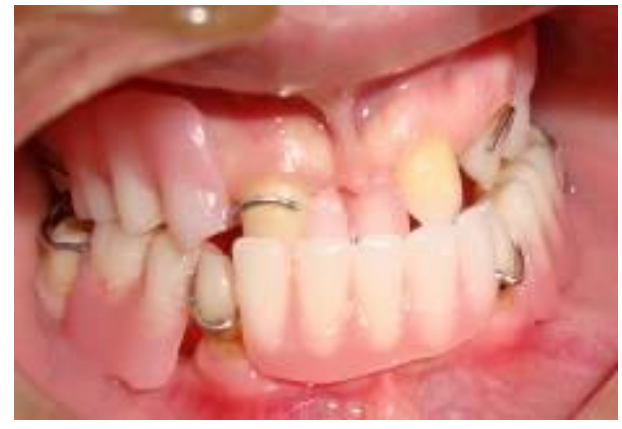

Resim 3c Protetik tedavi sonrası(Alt-üst çene)

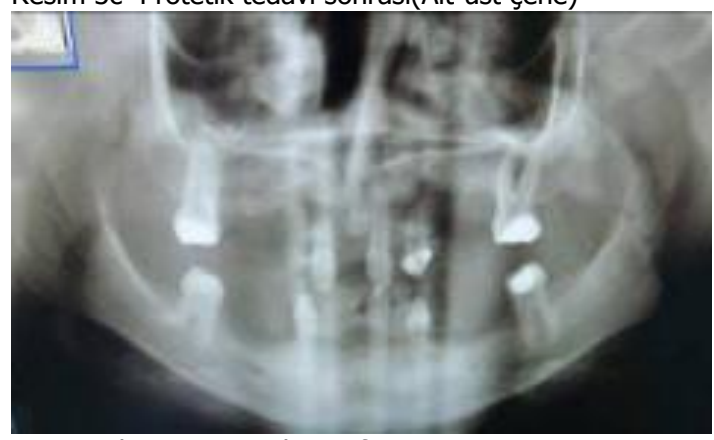

Resim 3d Hastanın radyografi görünümü

\section{OLGU 4}

6 yaşındaki erkek çocuk hastanın yapılan klinik ve radyolojik muayenesinde üst çenede toplamda 4 dişin bulunduğu ve bazı dişlerin gömük olduğu; ayrıca alt çenede dişlerin tamamının eksik olduğu tespit edilmiştir (Resim 4a,4b,4c). Buna ek olarak hastada semer burun, çıkıntılı dudaklar, kuru cilt ve deride döküntüler fark edilmiştir. Hastanın konik üst ön dişlerinin restorasyonu yapılmış ve oral rehabilitasyon eğitimi verilmiştir. Protetik değerlendirme sonrası üst çeneye hareketli parsiyel ve alt çenede de total protez uygulandı. (Resim 4d,4e). Hasta 6 aylık periyotlarla takip ediliyor.

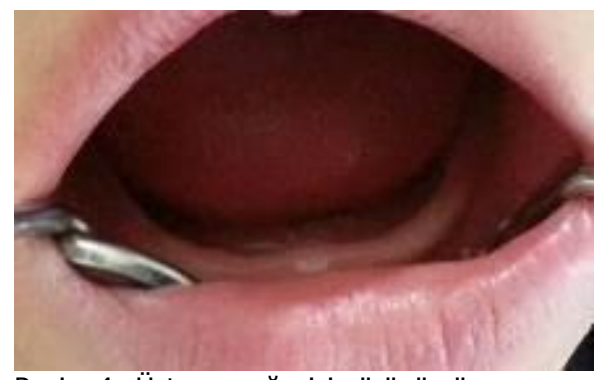

Resim 4a Üst çene ağız içi görünümü

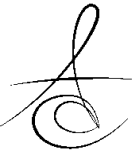


Atatürk Üniv. Diş Hek. Fak. Derg.

] Dent Fac Atatürk Uni

Supplement: 13, Yll: 2015, Sayfa : 10-17

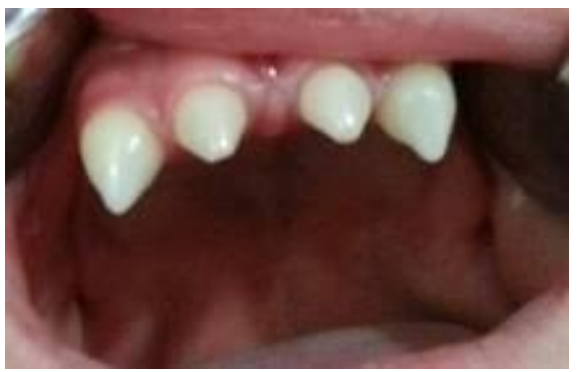

Resim 4b Alt çene ağız içi görünümü

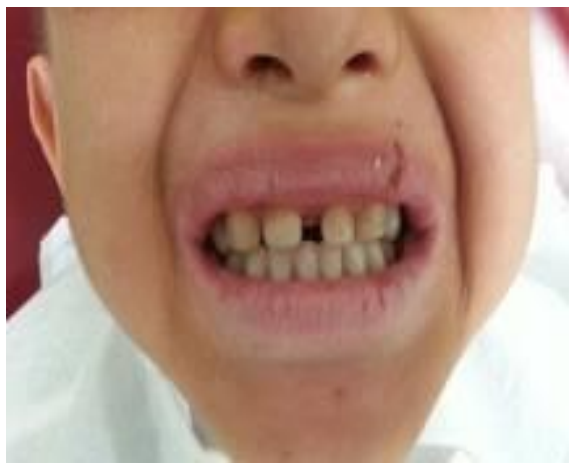

Resim 4c Hastanın radyografik görüntüsü.

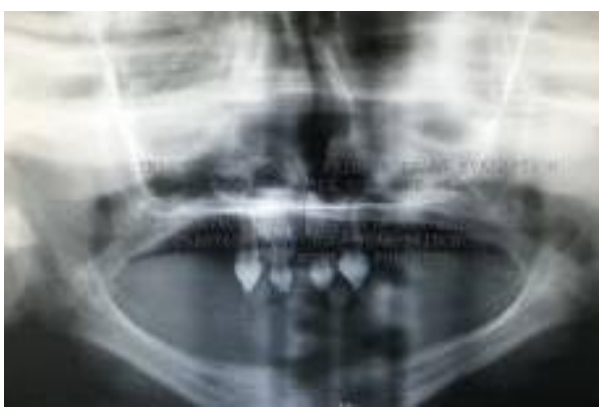

Resim 4d Tedavi sonrası görünümü

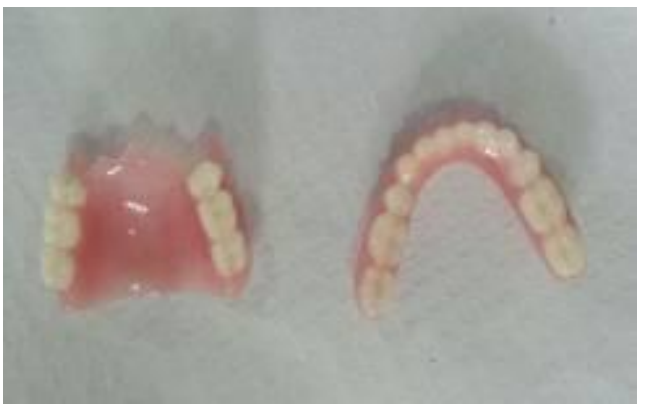

Resim 4e Hastanın alt-üst çene protezleri
DOĞAN, TANİK, ARAS, TOPTANCI, ARSLANOĞLU, ERATİLLA, GÜVEN,

ATAŞ, DEMİRCI

\section{OLGU 5}

12 yaşındaki kız çocuğu hastanın, yapılan klinik ve radyolojik muayenesinde diş eksiklikleri ve diş çürükleri olduğu görülmüştür. Hastanın oral muayenesinde ise $11,21,13,23,26,33,36,46$ nolu dişlerin olduğu görülmektedir (Resim $5 a, 5 b, 5 d$ ). Ayrıca hastanın ağız dışı muayenesinde kuru cilt, semer burun, anormal saç kılı, çıkıntılı dudaklar ve parmaklarında şekil bozukluğu olduğu görülmektedir (Resim 5c). Hastanın protetik değerlendirme sonrası fonksiyon, fonasyon ve estetik problemini iyileştirmek için alt ve üst çeneye hareketli parsiyel protezler uygulandı (Resim 5e). Hastanın fiziksel büyümesi göz önüne alınarak 6 aylık periyotlarla kontrolleri takip edilmektedir.

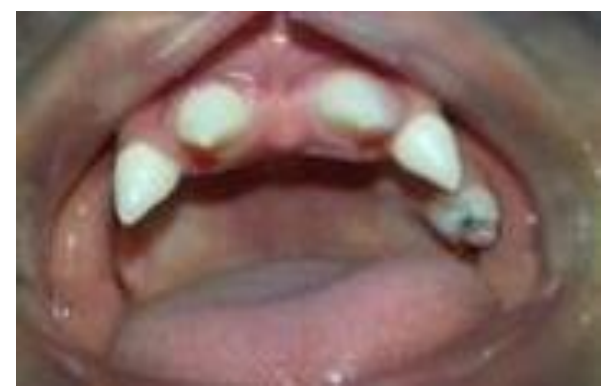

Resim 5a Üst çene intra-oral görünümü

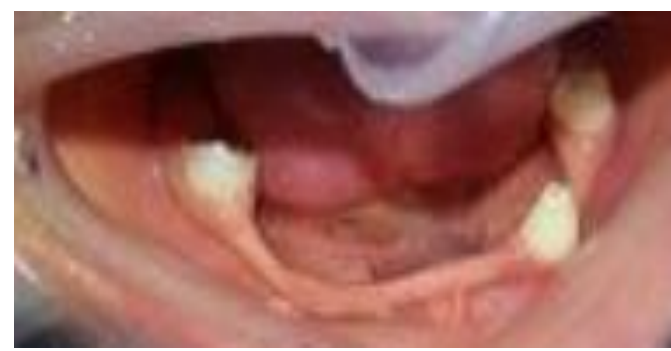

Resim 5b Alt çene intra-oral görünümü

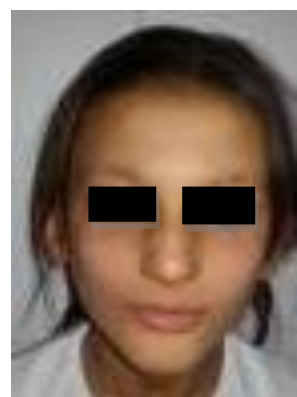

Resim 5c Hastanın frontal görünümü

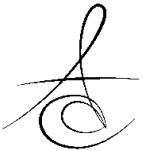


Atatürk Üniv. Diş Hek. Fak. Derg.

] Dent Fac Atatürk Uni

Supplement: 13, Yıl: 2015, Sayfa : 10-17

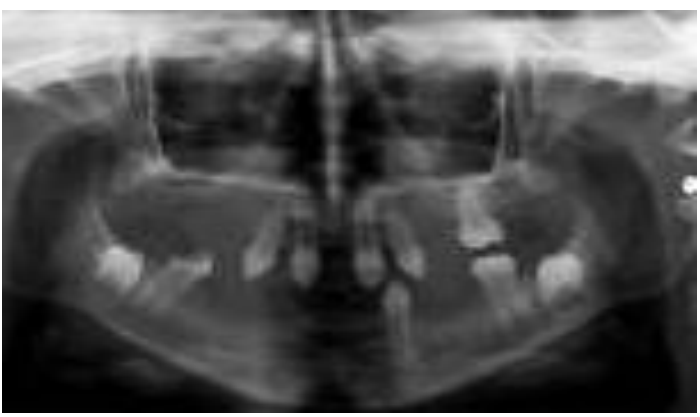

Resim 5d Hastanın panoramic görüntüsü

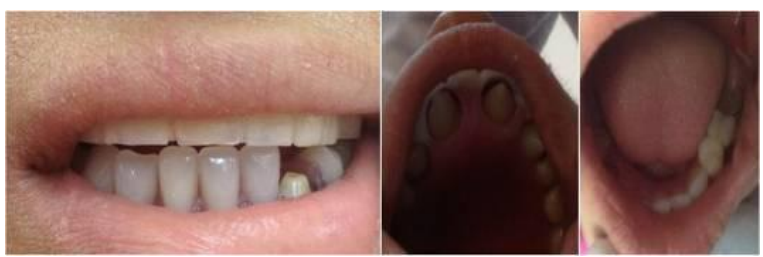

Resim 5e Tedavi sonrası görünümü

\section{TARTIŞMA}

Genetik bir hastalık olan ektodermal displazinin, $X$ kromozomuna bağlı geçiş gösterdiği için erkeklerde daha sık gözlendiği bildirilmiştir. Normal X kromozomu ile hastalıklı kromozom taşıyan kız olgular heterozigot olup, hastalığın belirtilerini genellikle eksik göstermektedir. ${ }^{1,15}$ Genetik taşıyıcılık modeli otozomal dominant, otozomal resesif ve $X$ kromozomuna bağlı resesif karakterler içerir. ${ }^{4,17} \mathrm{Bu}$ sendromun temel bulguları cilt, diş, tırnak ve saçlar ile ilgili deformitelerdir. Ayrıca, hastalarda yarık dudak / damak, ekstremite anomalileri, immünolojik bozukluklar ve zeka geriliği gibi değişken kusurlarda oluşabilir. ${ }^{9}$ Son dönemdeki çalışmalarda vakaların \%49'unda rekürrent otitis media ve \%43'ünde ses problemlerinin bulunduğu bildirilmiştir. $\mathrm{Bu}$ vakalarda akut faringo-larenjit ve pulmoner enfeksiyonlara yatkınlık rapor edilmiştir. ${ }^{18}$

Ektodermal displazili vakalarda en fazla diş eksikliğinin mandibulada ve cinsiyet olarak da erkeklerde olduğu bildirilmiştir. Tüm etkilenen erkeklerde maksiller keser dişlerin anormal kron formuna; molar dişlerin anormal kök formasyonuna da sahip olabileceği ve çoğunlukla taurodonti görülebileceği rapor edilmiştir. Genel olarak heterozigot kadınlarda normal verilerden önemli derecede küçük dişler gözlenmektedir. ${ }^{19,20}$

M. Nguyen-Nielsen ve ark. ${ }^{21}$ 11-18 yaş arası ektodermal displazili vakalar üzerinde yapmış olduğu epidemiyolojik çalışmada 1224 vakada diş anomalisi
DOĞAN, TANİK, ARAS, TOPTANCI, ARSLANOĞLU, ERATILLLA, GÜVEN, ATAŞ, DEMİRCI

\%79.4, hipotrikozis \%11.4 ve hipohidrozis \%5.9 olarak bulmuşlardır. Yavuz ve ark. ${ }^{22} 15$ vaka üzerinde yapmış olduğu bir çalışmada tüm vakalarda diş eksikliği, 12 vakada trikodisplazi, 13 vakada hipohidrozis ve 12 vakada anormal parmak ve tırnaklar bulmuşlardır.

Oral bölgedeki diş eksiklikleri nedeniyle alveol kretler ince ve gelişmemiştir. Bu nedenle dikey boyutta azalma ve dudaklarda şişkin görünüme sebep olduğu bildirilmiştir. ${ }^{1,15}$ Bizim olgularımızda semer burun, tırnaklarda deformiteler, terlemede azalma, dişlerde anomaliler ve dudaklarda şişkinlik görülmüştür.

Literatürde, süt ve daimi dişlerin birçoğunun eksikliği nedeniyle erken dönemde diş tedavisinin yapılması tavsiye edilmiştir. ${ }^{15}$ Olgularımızda mevcut dişlerin erken kaybına neden olabilecek durumlara engel olmak için koruyucu ve restoratif tedaviler yapılmalıdır.

Ruhin ve $a^{23}$. yapmış olduğu epidemiyolojik çalışmada, hastaların sefalometrik analizlerinde ciddi maksiller hipotrofi ve diş eksikliği olan vakalarda ise iskeletsel sınıf III olduğunu bildirmişlerdir.

ED hastalarının birçoğunda üst çenede yeterli keratinize dişeti dokusu yoktur. Posterior dişlerin ise, klinik kuron boyları kısadır. Diş çürükleri ve periodontal hastalıklar nadir olarak görülür. Klinik kuron boyu yeterli olmayan dişlerde kuron boyu uzatma işlemi ve bazı durumlarda serbest dişeti grefti ile keratinize dişeti dokusunun artırılması gerekebilir. ${ }^{24}$

ED hastaların tedavisinin planlanması, hazırlanması, tamamlanması ve var olan dişlerin sağlığının korunması zordur. Bu hastalarda planlanan diş destekli sabit parsiyel protezler için abutmentler hazırlanır. Abutmentli dişler periodontal olarak stabil tutulmalı ve ilerleyen zamanlarda marjinal kısımlarında gelişen çürükler, protezin başarısızlığı ile sonuçlanabilir. ${ }^{24}$

Yapılan çalışmalarda diş eksikliği için çocuk hastalarda hareketli parsiyel veya total protezler tercih edilmiştir. ${ }^{1,15}$ Diş eksikliklerinin olduğu vakalarda hareketli parsiyel protezler önerilmektedir. Yapılan protezler yeni süren dişler, alveolar gelişime, çenelerin rotasyonel gelişimine bağlı olarak periyodik olarak modifiye edilmelidir. ${ }^{25}$ Hareketli bölümlü protezler en çok başvurulan protetik tedavi şekli olmasına rağmen ED' li hastalarda implantlarda alternatif tedavi olabilir. ${ }^{17}$ Gelişimi tamamlanan ED hastalarında osseointegre implantlar protezi destekleme, stabilize etme ve tutuculuğu arttırma amaçlı kullanılabilirler. ${ }^{16}$ Sabit implant tutuculu protezlerin avantajlarına

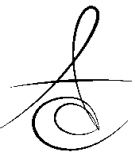


Atatürk Üniv. Diş Hek. Fak. Derg.

J Dent Fac Atatürk Uni

Supplement: 13, YIl: 2015, Sayfa : 10-17
DOĞAN, TANİK, ARAS, TOPTANCI, ARSLANOĞLU, ERATIILLA, GÜVEN, ATAŞ, DEMİRCÍ rağmen, bazı durumlarda hareketli implant tutuculu protezler endike olabilir. ${ }^{16}$ Fakat implant yaparken alveolar kemiğin yetersiz ve bıçak sıttı şeklinden dolayı greft ve sinüs lifting gibi ilave cerrahi işlemler gerekebilir. ${ }^{26}$ Büyüme gelişme çağındaki hastalarda ileriki zamanlarda implantın pozisyonu ve protez ile ilgili problemler de çıkabilir. ${ }^{27}$ Ayrıca bazen finansal kısıtlamalar ve başka öncelikler hastanın uygun tedaviyi seçmesini engelleyebilir. ${ }^{25}$

\section{SONUC}

Ektodermal displazi vakalarında diş eksikliği sık karşılaşılan durumlardan biridir. Bu nedenle hastanın sahip olduğu dişlere koruyucu tedavilerin yapılması meydana gelebilecek diş kayıplarını engelleme açısından önemli bir uygulamadır. Eksik dişler nedeniyle hastaların fonksiyon, fonasyon ve estetik problemleri oluşabilmektedir. Diş hekimliğinde konservatif ve protetik tedaviler hastaların sosyal ve psikolojik yaşamında oluşabilecek problemlerin ortadan kaldırımasında yararlı olmaktadır.

\section{KAYNAKLAR}

1. Altun C. 7 yaşındaki bir hidrotik ektodermal displazi hastasında protetik tedavi yaklaşımı (olgu raporu). Dicle Dişhekimliği Dergisi 2009;10: 25-8.

2. Yavuz I et al. Ectodermal dysplasia: Retrospective study of fifteen cases. Arch Med Res 2006 ;37:403-9.

3. Williams, C, et al. "Prosthodontic treatment strategy for patients with ectodermal dysplasia: A literature review." SRM Journal of Research in Dental Sciences 2014;5:46.

4. Baygın Ö, Ülker $E$, Tulunoğlu Ö.Ektodermal displazi: 4 olgu bildirimi. GÜ Diş Hek Fak Derg 2009;26: 59-65

5. Köymen G, Karaçay Ş, Başak F, Akbulut E, Aştun C. Ektodermal displazi olgusunda kombine dişsel tedavi. Gülhane Tıp Dergisi 2003; 45:79-81.

6. Akgün $\mathrm{M} \mathrm{A}$ et all. Multidisciplaniry treatment approach of patient with ectodermal dysplasia. J Int Dent Med Res 2010; 3:141-5.

7. Mortier K, Wackens G. Ectodermal dysplasia syndrome. Ned Tijdschr Tandheelkd 2003; 110: 190-2.
8. Huang, Peterson Y., and Carl F. Driscoll. "From childhood to adulthood: Oral rehabilitation of a patient with ectodermal dysplasia." The Journal of prosthetic dentistry 2014;112:439-43.

9. Yoshioka $T$ et al. Autosomal Dominant Anhidrotic Ectodermal Dysplasia with Immunodeficiency Caused by a Novel NFKBIA Mutation, p.Ser36Tyr, Presents with Mild Ectodermal Dysplasia and NonInfectious Systemic Inflammation. J Clin Immunol 2013;33:1165-74.

10. M. Callea et al. Ear nose throat manifestations in hypoidrotic ectodermal dysplasia. International Journal of Pediatric Otorhinolaryngology 2013;77: $1801-4$.

11. Johanna L. Molecular mechanisms of ectodermal dysplasia syndromes. Academic Dissertation Helsinki 2004.

12. Pande, N. A. "Prosthodontic rehabilitation of patient with hereditary ectodermal dysplasia. " Indian Journal of Dentistry 2012;3: 49-52.

13. Salinas TJ, Sheridan PJ, Castellon P, Block MS. Treatment planning for multiunit restorations The use of diagnostic planning to predict implant and esthetic results in patients with congenitally missing teeth. J Oral Maxillofac Surg 2005;63:4558.

14. Lypka M, Yarmand D, Burstein J, Tso V, Yamashita DD. Dental implant reconstruction in a patient of ectodermal dysplasia using multiple bone grafting techniques. J Oral Maxillofac Surg 2008; 66:12414

15. Över H., Akşit S. Ektodermal Displazide Hastalarda Protetik Rehabilitasyon: Olgu Sunumu Atatürk Üniv. Diş Hek. Fak. Derg 2012: 22; 180-184.

16. Başkan Ülkü Z., Yavuz İ. Ektodermal Displazili Hastalarda Protetik Yaklaşımlar . Atatürk Üniv Diş Hek Fak Derg 2011;21: 55-9.

17. Altun S, Altun Ş, Yavuz İ, Agüloğlu S . Ektodermal displazi: 3 vaka raporu. T Klin Diş Hek Bil Derg 2001;7:154-60

18. Robert Mills; Mary-Louise Montague; Lisa Naysmith. Ear, nose and throat manifestations of ectodermal dysplasia. The Journal of Laryngology and Otology 2004; 118: 406-8.

19. Mo. Lexner, A. Bardow, Jm. Hertz, La. Nielsen, S. Kreıborg, Anomalies of tooth formation in hypohidrotic ectodermal Dysplasia. International Journal of Paediatric Dentistry 2007; 17: 10-8. 
20. Nieminen, Pekka. Genetic basis of tooth agenesis. Journal of Experimental Zoology Part B: Molecular and Developmental Evolution 2009; 312: 320-42.

21. M. Nguyen-Nielsen et al. The prevalence of Xlinked hypohidrotic ectodermal dysplasia (XLHED) in Denmark, 1995-2010. European Journal of Medical Genetics 2013;56: 236-42.

22. Yavuz I et al. Ectodermal dysplasia: Retrospective study of fifteen cases. Arch Med Res 2006; 37: 403-9.

23. Ruhin, B., et al. Pure ectodermal dysplasia: retrospective study of 16 cases and literature review. The Cleft palate-craniofacial journal 2001;38: 504-18.

24. Sclar, Anthony G., et al."Treatment planning and surgical considerations in implant therapy for patients with agenesis, oligodontia, and ectodermal dysplasia: review and case presentation. Journal of Oral and Maxillofacial Surgery 2009;67: 2-12.

25. Murdock S, Lee JY, Guckes A, Wright JT. A costs analysis of dental treatment for ectodermal dysplasia. J Am Dent Assoc 2005; 136: 1273-6.

26. Worsaac N, Jensen BN, Holm B, Holsko J. Treatment of severe hypodontia-oligodontia: An interdisciplinary concept. Int J Oral Maxillofac Surg 2007; 36: 473-80

27. Pavarina AC, Machado AL, Vergani CE, Giampaolo ET. Overlay removable partial dentures for a patient with ectodermal dysplasia: A clinical report. J Prosthet Dent 2001; 86: 574-7.

\author{
Yazışma Adresi \\ Dr. Abdulsamet TANİK \\ Dicle Üni. Diş Hekimliği Fakültesi \\ Periodontoloji Anabilim Dalı. \\ Diyarbakır/ Sur \\ TIf: 0412 - $2488101-06$ \\ E-mail: samet.120a@gmail.com
}

